\title{
Os processos de (re)tradicionalização e patrimonialização no carnaval dos blocos de rua no Rio de Janeiro
}

\author{
Los procesos de (re)tradicionalización y patrimonialización \\ en el carnaval de los bloques de calle en Río de Janeiro
}

\section{The processes of (re)traditionalization and patrimonialization in the carnival of the blocks of street in Rio de Janeiro}

\author{
Marina Bay Frydberg'
}

\footnotetext{
Palavras chave:

Carnaval

Tradição

Patrimônio
}

Resumo:

O século $X X I$ trouxe consigo a expansão do carnaval dos blocos de rua na cidade do Rio de Janeiro em proporções cada vez mais expressivas, tanto no número de blocos quanto no de foliões. Inseridos nesta recente valorização de brincar o carnaval, os blocos de rua na cidade do Rio de Janeiro se veem em meio a uma discussão entre o aumento da rentabilidade econômica através da mercantilização da/na festa, associada à sua profissionalização, e a valorização de práticas tradicionais de se brincar o carnaval através da discussão da sua patrimonialização. Busca-se, a partir desse panorama, compreender o processo de (re)tradicionalização pelo qual vem passando o carnaval dos blocos de rua na cidade do Rio de Janeiro, problematizando os múltiplos significados que a noção de tradição carnavalesca tem para os diferentes agentes que organizam a festa e suas ações pela patrimonialização da festa. 


\section{Resumen:}

El siglo XXI trajo consigo la expansión del carnaval de los bloques de calle en la ciudad de Río de Janeiro en proporciones cada vez más expresivas, tanto en el número de bloques y de folios. En los últimos años se ha convertido en una de las principales causas de la crisis económica mundial, que se ha convertido en una de las principales causas de la crisis económica mundial. tradicionales de jugar al carnaval a través de la discusión de su patrimonialización. Se busca, a partir de ese panorama, comprender el proceso de (re) tradicionalización por el cual viene pasando el carnaval de los bloques de calle en la ciudad de Río de Janeiro. Problematizando los múltiples significados que la noción de tradición carnavalesca tiene para los diferentes agentes que organizan la fiesta y sus acciones por la patrimonialización de la fiesta.
Palabras clave:

Carnaval

Tradición

Patrimonio

\section{Keywords:}

Carnival

Tradition

Heritage

\section{Abstract:}

The XXI century brought with it the expansion of the carnival of the blocks of street in the city of Rio de Janeiro in ever more expressive proportions, as much in the number of blocks as of revelers. Inserted in this recent valorization of playing the carnival, the blocks of street in the city of Rio de Janeiro are seen in the middle of a discussion between the increase of economic profitability through the commercialization of the party, associated to its professionalization, and the valuation of practices traditional way of playing the carnival through the discussion of its patrimonialization. From this perspective, one seeks to understand the process of (re) traditionalization through which the carnival of street blocks in the city of Rio de Janeiro has been passing. Problematizando the multiple meanings that the notion of carnival tradition has for the different agents who organize the party and its actions for the patrimonialization of the party. 


\section{Os processos de (re)tradicionalização e patrimonialização no carnaval dos blocos de rua no Rio de Janeiro}

\section{Introdução}

O Um dos músicos do bloco Orquestra Voadora, considerado por alguns um bloco tradicional e por outros como expressão do fim da tradição do carnaval dos blocos do Rio de Janeiro, define a importância da discussão sobre os processos de tradicionalização pelo qual o carnaval de rua vem passando.

Eu entendo esse tradicionalismo, a gente enraizar uma tradição. Mas eu não sei se funciona. Porque assim, no carnaval não existe uma forma só de brincar o carnaval. O carnaval acontece não só no Brasil. Ele acontece em várias partes do mundo. Então assim, no Rio de Janeiro a gente tem blocos de marchinhas de samba. Em Pernambuco a gente tem bloco de maracatu, de frevo, de coco, de ciranda. Na Bahia tem blocos de afoxé, de ijexá. Na Colômbia vão ter blocos de cumbia. No México você vai ter blocos tocando música tradicional mexicana. Então é difícil você dizer que para ser um bloco de carnaval você tem que ter isso! Tem que tocar essa música, tem que ter o estandarte. Eu acho legal deixar isso registrado. Eu acho legal que você registre como: o carnaval tradicional do Rio de Janeiro se faz assim. Mais como registro, mas não como uma regra.

(Tiago Rodrigues, bloco Orquestra Voadora, em entrevista para a pesquisa.)

$\mathrm{Na}$ cidade do Rio de Janeiro no carnaval de 2016 foram contabilizados 587 desfiles de 505 blocos", embora esse número seja um tanto maior já que muitos blocos não são contabilizados pelos agentes públicos que organizam o carnaval carioca, acontecendo muitas vezes em posição de questionamento a estes agentes. O carnaval carioca"', segundo dados da RIOTUR (Empresa de Turismo da cidade do Rio de Janeiro), mobilizou mais de cinco milhões de foliões para a rua em 2016, sendo um milhão de turistas. Pelo lado econômico, movimentou três milhões de dólares. Em proporções cada vez mais expressivas, tanto no número de blocos quanto de foliões, o carnaval dos blocos de rua na cidade do Rio de Janeiro vem vivendo uma expansão no calendário anual da festa que impulsiona uma nova organização da celebração carnavalesca, tanto por parte do poder público quanto dos blocos. Inserida nesta recente valorização de brincar o carnaval, os blocos de rua na cidade do Rio de Janeiro se veem em meio a uma discussão entre o aumento da rentabilidade econômica através da mercantilização da/na festa, associada à sua profissionalização, e a valorização de práticas tradicionais de se brincar o carnaval através da discussão da sua patrimonialização.

Este artigo $\vee$ busca, a partir desse panorama, compreender o processo de (re)tradicionalização pelo qual vem passando o carnaval dos blocos de rua na cidade do Rio de Janeiro, problematizando os múltiplos significados que a noção de tradição carnavalesca tem para os diferentes agentes que organizam a festa ${ }^{\mathrm{V}}$.

O carnaval dos blocos de rua tornou-se, assim, um campo de disputas pelos significados que envolvem a ideia de tradição, que são transformadas em ações oficiais legalistas - impulsionadas pelo poder público e pelas ligas/ associações - de patrimonialização da festa. Explorar como se constrói no nível do discurso, a ideia do que poderíamos 
entender por tradicional no carnaval dos blocos de rua do Rio de Janeiro, será aqui apresentada a partir dos principais agentes envolvidos na organização da festa - blocos, ligas/associações, e poder público - buscando traçar a linha que liga o discurso sobre a tradição carnavalesca com ações de patrimonialização da festa nos blocos de rua.

\section{Tradição e Blocos: Entre noções estéticas, históricas e territoriais}

Entendendo que ao falar de blocos de rua hoje no Rio de Janeiro estamos falando de um todo heterogêneo, envolvendo mais de 652 blocos ${ }^{\mathrm{VII}}$, com percepções distintas do que seria a tradição carnavalesca. Desta forma, não pretendo aqui desenvolver a noção de tradição em todos os blocos, tarefa muito mais ampla do que a proposta deste artigo e da própria intenção da pesquisa, mas analisar a partir do discurso de alguns representantes de blocos como são construídas certas noções sobre a tradição e a consequente classificação interna entre os blocos que respeitam ou não esta noção. Todavia para entender esse processo de tradicionalização dos blocos é preciso recuperar um pouco da história dessa manifestação cultural, já que em um primeiro momento a tradição é associada a antiguidade.

A tradição de se brincar o carnaval foi trazida para o Brasil pelos portugueses e ganhou força a partir da vinda da família real em 1808. Até 1840, segundo Queiroz (1999), o entrudo centralizava as atenções durante os dias de carnaval, os dias gordos. Tratava-se de uma comemoração urbana que envolvia criar combates utilizando objetos e materiais que sujassem. Com o tempo a forma de festejar foi mudando, o que faria desaparecer o entrudo no início do século XX. Este modo popular de brincar o carnaval, vai sendo progressivamente substituído, como denomina Queiroz (1999), pelo Carnaval Veneziano ou Grande Carnaval, que inspirado nos bailes de máscaras da Europa acontecia nas sociedades carnavalescas, também conhecidas como clubes. As camadas populares também criaram novos modelos de brincar o carnaval. Queiroz (1999) entende que somente com o crescimento ao longo dos anos do Pequeno Carnaval, principalmente com os ranchos, os cordões, os blocos e, posteriormente, as escolas de samba, que foi possível a integração de camadas sociais inferiores nas comemorações.

Esse carnaval tradicional trazido de Portugal, ganhou características específicas ao modo de vida local e, desde o seu início, construiu a festa carnavalesca nas ruas das cidades brasileiras. O carnaval dos blocos de rua que surgiu no início do século $X X$ na cidade do Rio de Janeiro, passou por momentos de valorização e esquecimento durante mais de um século de história. Propomos indicar quatro momentos distintos na história dos blocos de rua no Rio de Janeiro (FRYDBERG; EIRAS, 2015) e da construção das suas tradições. Tradição aqui entendida no sentido de Hobsbawm (1984) dá para as tradições inventadas:

O termo "tradição inventada" é utilizado em um sentido amplo, mas nunca indefinido. Inclui tanto as "tradições" realmente inventadas, construídas e formalmente institucionalizadas, quanto as que surgiram de maneira mais difícil de localizar em um período limitado e determinado de tempo - as vezes coisas de poucos anos apenas - e se estabelecem com enorme rapidez. (HOBSBAWM, 1984, p. 9)

O primeiro momento que representa a criação dos primeiros blocos e que tem como referência o Cordão da Bola 
Preta, maior e mais antigo bloco em funcionamento na cidade, fundado em 1918. Este período de consolidação do carnaval de rua na cidade ocupa as primeiras décadas do século passado. Temos um segundo momento em termos de criação de blocos que vai da década de 40 até meados dos anos 60 , período de início do seu declínio, muito influenciado pelo cenário político da instauração do golpe militar de 1964. São fundados, nesse segundo momento, blocos tradicionais com o Bafo de Onça (1956), Cacique de Ramos (1961) e Banda de Ipanema (1965).

A cidade do Rio de Janeiro viveu dois momentos de retomada dos blocos, o primeiro no início dos anos 80 , reflexo do processo de redemocratização que o país passou, com a criação de um grande número de blocos e o deslocamento da festa para a zona sul da cidade. Foram criados nesse terceiro momento, blocos hoje considerados tradicionais como Bloco dos Barbas (1981), Simpatia é quase amor (1985) e Suvaco do Cristo (1986). E o segundo boom acontece a partir dos anos 2000 (HERSCHMANN, 2013), depois de um declínio do carnaval nos anos 90 por conta da violência na cidade, e que permanece com força até os dias de hoje. Os blocos que iniciaram esse quarto momento de retomada do carnaval foram criados no final dos anos 90 e início dos anos 2000 e já são considerados tradicionais, como o Cordão do Boitatá (1996), Monobloco (2000) e MuIheres de Chico (2006), primeiro bloco temático a ser criado.

É ampla a esfera de possibilidade de classificação de um bloco como tradicional por conta do ano e do momento de sua criação, mesmo que possa haver nuances entre a noção de tradição, construindo-se uma gradação entre mais ou menos tradicionais, consideram-se blocos tradicionais do Cordão da Bola Preta, fundado em 1918, ao Mulheres de
Chico, fundado em 2006. Essa noção de tradição presente nos blocos de rua tem como parâmetro a história do bloco em termos do ano da sua fundação e associada a ela determinada prática carnavalesca. Preceitos estes que são flexíveis e, principalmente, contextuais e relacionais. Assim, um mesmo bloco pode ou não ser considerado tradicional dependendo de quais são as referências de comparação para essa classificação.

Os membros dos blocos estão construindo através de suas falas uma série de parâmetros para a classificação destes segundo seu nível de tradição. Associado ao caráter histórico, muitas vezes para dar força a ele, está também o caráter territorial. Ou seja, um bloco não é tradicional exclusivamente por conta de quando ele foi criado, mas também pela ligação com o lugar que ele desfila. Assim essa tradição dos blocos passa a ser territorializada e associada de forma direta aos territórios específicos da cidade.

É uma tradição. É uma relação com o lugar. Relação de pertencimento. Os caras são músicos, entram no carro de som e saem. Eles não têm uma relação com aquele espaço onde eles estão. Essa é a grande diferença.

(Alvanísio Damasceno, bloco Carmelitas, em entrevista para a pesquisa.)

Desta forma, com a associação entre história e território a tradição serve como construtora de um modo específico de ser no carnaval, uma identidade para a prática carnavalesca. Essa tradição carnavalesca é elaborada de forma muito semelhante com o que Hobsbawm (1984) denominou de invenção das tradições, ou seja, uma estruturação de práticas simbólicas que ligam o presente com um passado determinado. Sendo assim, todos os blocos que se vinculam com uma prática do passado carnava- 
lesco, podem ser entendidos como tradicionais, no sentido de uma tradição inventada. Essa associação a um passado pode acontecer a partir de três elementos: da música, do uso de fantasias e da espontaneidade.

Talvez seja essa que eu defina de uma essência carnavalesca. Acho que tem que ter música, dança e fantasia, são três coisas que se vai com o enfoque que você quiser dar, mas as pessoas têm que ouvir música, as pessoas têm que mover com o seu corpo. É a festa da dança, da reunião dos corpos em comunicação. Acho que isso é carnaval. Acho que ficar no entorno dos bares na conversa ainda com uma máscara, com a fantasia e enchendo a cara é uma forma carnavalesca de estar ainda. Acho que é isso, o carnaval em si requer música, fantasia e movimento de corpo.

(Yeda Dantas, bloco Gigantes da Lira, em entrevista para essa pesquisa. )

Elementos estéticos e artísticos como a música tocada pelos blocos e o uso de fantasias auxiliam na construção da tradição, na sua reprodução e, principalmente, na sua representação. Consolidam-se como tradições inventadas no sentido dado por Hobsbawm (1984) quando podemos identificá-las como uma série de práticas rituais e simbólicas que seguem regras que as ligam a um passado histórico específico. Essa continuidade com o passado tem que ser construída no presente como "reações a situações novas que ou assumem a forma de referência a situações anteriores, ou estabelecem seu próprio passado através da repetição quase que obrigatória" (HOBSBAWM, 1984 p.9).

A questão musical pode tornar-se fundamental, para alguns blocos, na determinação do tradicional. Tocar samba, marchinhas e/ou variações desses ritmos são características que podem fazer um bloco ser considerado tradicional, ou nem mesmo bloco de carnaval.

Tradição do carnaval pra mim é farra! É a brincadeira, é a farra, entende. E a gente sente que o, até dentro da Sebastiana, tem bloco que defende mais os blocos de música, tem blocos que são mais contrários. Eu to mais no lado dos contrários, mas não pára acabar com isso, mas eles talvez tenham que ter outro nome, não é um bloco de rua, digamos assim. Por exemplo, o Monobloco pra mim não é um bloco de rua, estão tocando na rua. A Preta Gil também não é um bloco. É a Preta Gil em cima de um trio elétrico, entendeu? [...] Só que não dá pra chamar de a mesma coisa. Acho que tem que ter essa origem da farra e passa pela música. E não a origem a música que passa pela farra. Acho que tem esse movimento contrário.

(Alvanísio Damasceno, bloco Carmelitas, em entrevista para a pesquisa.)

Todavia essa discussão estética musical como característica distintiva de tradição não é vista para todos os blocos da mesma forma. Alguns representantes de blocos, principalmente dos blocos fundados no quarto momento, não identificam como necessário um repertório musical específico para ser considerado bloco tradicional. O que constrói a noção de tradição é a espontaneidade da festa, expressa seja no samba como no rock.

Isso é uma coisa que eu falo sempre, eu acho que carnaval antes de qualquer coisa é uma data. São aqueles 40 dias antes da páscoa que as pessoas tradicionalmente aproveitam para extravasar. Então o carnaval é o momento de extravasar e se permitir. Vou me fantasiar, bandido vira herói, rico vira pobre, pobre vira rico, santa vira puta. 
Então é o momento que tem que extravasar, extravasar mesmo, colocar a alegria pra fora. Pra mim, o carnaval, o carnaval tradicional é um momento que tem espaço pra isso, independente de gênero musical. Porque a pessoa que tá lá ouvindo rock é a forma dele extravasar. "Ah! O carnaval é pegação!". Tem coisa mais primitiva que pegação? Deixa o povo se pegar. Pra mim o carnaval tradicional é esse. $O$ carnaval que você se diverte.

(Cristina Couri, bloco Desliga da Justiça, em entrevista para essa pesquisa.)

Assim o carnaval da desordem representa o carnaval da tradição, sustentado na ideia da possibilidade de inversão da ordem social (BAKTHIN, 1993). Todavia a noção central deste argumento, independente de especificidades estético musicais, está na valorização da tradição através da noção de espontaneidade, mesmo que atualmente o carnaval dos blocos de rua seja cada vez mais organizado e profissionalizado.

Eu acho que é o nosso, é um carnaval sem muitas responsabilidades. É um carnaval na rua, que você sai fantasiado, que você tem a sua bateria, o seu samba e não tem muita ordem. Tem uma certa desordem. Esse é um carnaval tradicional de rua do Rio de Janeiro. Você entra com camiseta, sem camiseta. Você sai a hora que quer, você entra a hora que quer. Começa acaba, é isso aí, esse é o carnaval que você poderia dizer como tradicional. (João Avelleira, bloco Suvaco do Cristo, em entrevista para essa pesquisa.)

Junto à noção de história, data de fundação do bloco, e de território, ligação do bloco com uma região da cidade, a tradição está aqui sendo construída como prática espontânea de brincar o carnaval. Espontaneidade construída pelos blocos com organização e profis- sionalismo, mas que serve como característica distintiva do carnaval dos blocos de rua do Rio de Janeiro com relação a outros carnavais de rua. A tradição dos blocos de rua também ganha recortes estéticos, na valorização das fantasias, e permanece em disputa com relação aos estilos musicais.

\section{Tradição e as ligas/associações: Das ações de patrimonialização ao direito à cidade}

As ligas/associações são formas coletivas e colaborativas de reunião de blocos com o objetivo de ampliar seu poder de negociação tanto com o poder público como com possíveis patrocinadores. Mas as ligas/associações também exercem poder no exercício da definição dos limites sobre a prática carnavalesca, ajudando assim na criação da noção de tradição. Seja pelos critérios estabelecidos pelas ligas/associações para a entrada de blocos, pela pressão junto ao poder público, pelos critérios para a autorização dos blocos para desfilar segundo noções de tradição, ou de manifestos contra as formas que o carnaval de rua tem tomado, esse grupo de blocos também possui visões diversas para a tradição. E inserem-se, assim, nesse campo de disputa pelo termo e pelos caminhos possíveis que o próprio carnaval pode seguir.

Embora com visões distintas sobre tradição, as ligas/associações disputam essas representações no nível do discurso e de ações mais efetivas, sejam associadas ao poder público ou de forma direta contra as ações do mesmo. Ligas/ associações como a Sebastiana, a Folia Carioca e os Amigos do Zé Pereira pensam a tradição dos blocos e do carnaval a partir da preservação de suas práticas e da formulação de limites para a festa. Esses limites podem ser, assim como 
nos blocos, históricos e territoriais, mas a ação para o respeito desses limites está vinculada com o estabelecimento de diálogos e pressões com o poder público, especificamente a Prefeitura Municipal do Rio de Janeiro.

A Zona Sul começou a ficar muito incomodada porque além dos blocos que já existiam na Zona Sul, todo mundo começou a querer desfilar na Zona Sul. Então o AfroReggae foi desfilar em Ipanema. A Preta Gil, que surgiu do nada, foi desfilar em Ipanema. O Sargento Pimenta, que também surgiu assim do nada, foi desfilar no mesmo lugar e no mesmo dia que o Bloco de Segunda, que tem 28 anos. Entendeu? Como é que você faz pra decidir naquele espaço público, na territorialidade, quem tem direito ou não? Aí começa a precisar de uma regra porque se eu to disputando com você o mesmo espaço, qual é a regra? A prefeitura decidiu, a regra é a antiguidade.

(Rita Fernandes, presidente da Sebastiana e do bloco Imprensa que eu gamo, em entrevista para pesquisa.)

Mas a disputa também pode acontecer no campo da discussão estética e musical, o que faz essas ligas/associações não utilizarem os mesmos critérios sobre o que pode ou não ser feito no carnaval dos blocos de rua do Rio de Janeiro.

Eu acho interessante. Com base em determinadas características, né, que eu já falei. A matriz do samba, a batucada, que não seja de cunho comercial, que não tenha abadá. De preferência que não tenha trio elétrico, que não tem nada a ver com o Rio de Janeiro. Entendeu? Elétrico devia ser proibido. Uma coisa é trio elétrico, outra coisa é carro de som. Praticamente todos tem carro de som, não tem trio elétrico. Chama de trio elétrico, mas poucos têm. Um ou outro que tem guitarrista, essa coisa axé, baiana. Mas poucos têm trio.

Ricardo Rabelo, presidente da Associação Folia Carioca e do Bloco Bafafá, em entrevista para a pesquisa.

Hoje em dia, tradição se mistura com o que ela se transformou. Tradicionalmente era um carnaval que tocava samba tradicional, em todas as regiões da cidade. Isso não acontece mais. Continua acontecendo sim, muito mais do que acontecia, graças a essa diversidade e explosão que aconteceu. O samba ocorre na cidade muito mais do que acontecia há 15 anos atrás, mas várias outras coisas também acontecem, vários outros blocos de várias maneiras, das formas mais bizarras. Até bloco de sertanejo universitário tem. [...] Como eu falei, não tá escrito em lugar nenhum. Ele se mantém muito na base da conversa, na base da troca de informações. Nós não vamos aceitar isso, não queremos isso. Aí, entra muito com a prefeitura próxima dos blocos também pra ouvir essa opinião e ajudar a criar canais de veto. A Cláudia Leite queria fazer um bloco, pra 100 milhões de pessoas, vai destruir a cidade. Isso é um critério que a prefeitura usa um pouco pra conseguir travar esse tipo de iniciativa. O único que tem mesmo é o da Preta Gil.

(Rodrigo Resende, presidente da Liga dos Amigos do Zé Pereira, em entrevista para a pesquisa.)

Mesmo com divergências com relação a padrões estéticos musicais que podem fazer parte do carnaval carioca, ambas as ligas/associações trabalham com a ideia de estabelecer limites para a incorporação de novos ritmos musicais (axé ou sertanejo) e formas produção (trio elétrico) no carnaval de rua do Rio de Janeiro. Nessa construção relacional 
da noção de tradição do carnaval de rua do Rio de Janeiro com o carnaval de Salvador, começa a ser construída a categoria acusatória baianização, entendida por alguns como a venda de camisetas ou abadás e o uso de cordas isolando quem as possui. Ou ainda o entendimento de que o modelo do carnaval baiano é o carnaval que já sucumbiu à lógica do mercado sofrendo um processo de comercialização/mercantilização da festa. Esta dicotomia entre o carnaval dos blocos de rua na cidade do Rio de Janeiro, pensado como manifestação cultural, em oposição a uma comercialização/mercantilização apontada no carnaval baiano, aparece de forma explícita na fala de blocos, ligas/associações, poder público e mídia. A baianização, ou melhor a luta para que ela não aconteça, é uma ação central das ligas/associações, unificando a todas na ordem do discurso, mas não na forma de agir.

No momento em que você coloca um bloco na rua, ele é pra quem quiser entrar. Afinal, a rua é pública. Se você $e$ os seus amigos querem festejar daquela forma, é uma festa pública. Naturalmente, você está obrigado a receber quem chega. Então você não pode colocar uma corda ou delimitar um território. Se você quer delimitar um território, você vai fazer uma festa fechada num lugar fechado.

(Rita Fernandes, presidente da Sebastiana e do bloco Imprensa que eu gamo, em entrevista para pesquisa.)

Umas das ações diretas em defesa do carnaval dos blocos de rua e contra o modelo da baianização do carnaval é a patrimonialização da festa de rua no Rio de Janeiro. Para isso a Sebastiana entrou com um pedido junto ao IPHAN (Instituto de Patrimônio Histórico e Artístico Nacional) para reconhecer o modo tradicional de brincar o carnaval dos blocos de rua no Rio de Janeiro como patri- mônio imaterial do Brasil. Através do reconhecimento de uma tradição e de seu valor histórico e simbólico, o carnaval dos blocos de rua se protegeria do possível desgaste gerado pelo efeito moda e, principalmente, de uma possível descaracterização das suas tradições. Com essa ação a Sebastiana oficializa o entendimento de que existam modos mais ou menos autênticos e tradicionais de brincar o carnaval dos blocos e, desta forma, blocos mais ou menos legítimos da tradição desta festa.

Nosso segundo movimento, foi esse de levar a ideia pro IPHAN pelo seguinte: quando começa este momento de comercialização do carnaval e de certa banalização do tema porque o tema está balizado. Nós não estamos gostando disso. Está banalizado na mídia, na própria ação dos blocos. A gente começou a achar que precisávamos fazer um movimento ideológico pra que a gente preservasse o carnaval na sua essência e nas suas características originais. Daí surgiu a ideia do IPHAN. "Vamos pedir pra transformar em patrimônio, em patrimônio imaterial do Rio e depois do Brasil". Como a gente já tava juntando material pra memória, vimos que era o mesmo caminho.

(Rita Fernandes, presidente da Sebastiana e do bloco Imprensa que eu gamo, em entrevista para pesquisa.)

Ao entendermos a busca pela patrimonialização dos blocos de rua como maneira pela qual se vai preservar a memória e a prática de carnavais de outros tempos, não se pode deixar de pensar na memória como construção, em que se operam lembranças e esquecimentos, e que só pode ser compreendida enquanto um campo de disputa (POLLAK, 1989; 1992). Esta disputa da memória quando associada a um sentimento de identidade passa a ter que ser ainda mais identifi- 
cada a um campo de disputas entre grupos políticos diversos (POLLAK, 1992, p. 205). Estes grupos políticos diversos estão aqui através das ligas/associações disputando uma memória sobre o carnaval de rua do Rio de Janeiro para através de ações de patrimonialização, ou seja, de reconhecimento e preservação dessa memória, construírem o autêntico carnaval dos blocos de rua do Rio de Janeiro.

O caminho trilhado pela Desliga dos Blocos para preservação da memória é distinto da Sebastiana, embora ambas busquem a preservação do modo tradicional de brincar o carnaval. Neste campo de disputas a Desliga busca preservar a tradição através da retomada de um carnaval de outra escala, espontâneo e que não passe pela organização e consequente mercantilização da/na festa carnavalesca. A Desliga foca suas ações em um embate mais direto com o poder público, principalmente através da exigência por parte da prefeitura de autorização para que os blocos possam desfilar, o que eles acusam de um processo de burocratização da festa.

Aquilo que eu via quando era criança pequena pode acontecer hoje, os blocos se juntavam, não tinham estandartes. Chegava uma pessoa tocando, juntava uma galera e se formava o bloco. O carnaval do Rio tem que se pensar nesse aspecto. Agora, a gente acha que decretos que limitam a espontaneidade do carnaval e impõem a ele uma atrelação ao mercado são nocivos e não fazem sentido. Decisão judicial pra defender carnaval também é uma coisa que não cabe. Um fórum que se discuta carnaval, nunca houve um sério. Eu nunca vi a prefeitura sentar numa mesa e discutir seriamente carnaval.

(Luís Otávio, representante da Desliga dos Blocos e do bloco Boi Tolo, em entrevista para a pesquisa.)
Através do discurso de valorização da tradição esse grupo defende a ocupação da cidade, e consequentemente do espaço público, de forma espontânea sem normas e legislações. A maioria dos blocos associados a Desliga dos Blocos sai no carnaval sem pedir autorização para a prefeitura e sem seguir o calendário e a organização do poder público. Eles organizam eventos paralelos como a "Abertura oficial do carnaval não oficial" e uma série de bloqueatas, ou seja, passeatas de blocos que transformam o carnaval em um espaço de luta política. Eles defenderam em manifesto publicado no blog da liga/ associação em 2010 que:

O carnaval de rua é festa do povo. É feito pelo povo e para o povo. Manifestação de espontaneidade, criatividade genuína e espírito livre. Nos dias de folia devemos respeito à Sua Majestade, o Momo. Não ao personagem raquítico que ultimamente tenta nos ensinar a brincar, como se ele próprio soubesse, mas ao mitológico, roliço, guloso, amante dos prazeres da carne e da alma, àquele que nos mostra que, ao contrário do que muitos pensam, no carnaval é quando se tiram as máscaras. Assim, há uma troca de ordem. Sai de cena a ordem careta, elitista e monetarizada e, em seu lugar, entra a ordem de Momo e a ordem do Rei é sambar quatro dias sem parar.

\section{[...]}

O decreto 32.664 da Prefeitura aprofunda o ataque à liberdade criativa e à espontaneidade do carnaval do Rio e o processo de "bahianização" da festa, ao obrigar os blocos a pedir autorizações com seis meses de antecedência e a cumprir inúmeras exigências, que arrepiariam até mesmo uma empresa estabelecida, ainda mais os pequenos blocos. A essência está sendo sufocada pelo dinheiro.

Manifestamos aqui que não reconhecemos esse decreto que, além de 
tratar desiguais como iguais, fere a Constituição e a tradição e cultura do povo carioca.

(DESLIGA DOS BLOCOS DO RIO DE JANEIRO - MANIFESTO MOMESCO)

Compartilhando com Lefebvre (1991) o argumento de que todos possuímos direito à cidade e à vida urbana, essa apropriação da cidade pela festa é defendida pela Desliga dos Blocos como um direito, o único durante o ano, em que o povo pode vivenciar a cidade de outra forma. A cidade, que durante o tempo do cotidiano se mostra excludente e segregadora, no tempo da festa, ou seja, durante o carnaval de rua, transforma-se em um espaço e um tempo próprio. É na defesa dessa espacialidade e temporalidade própria do carnaval de rua que a Desliga dos Blocos constrói seu argumento contra essa prática de comercialização/mercantilização do carnaval carioca dos blocos expressa na categoria acusatória baianização.

Outro manifesto também foi distribuído pela Desliga dos Blocos, novamente defende a ocupação da cidade e do espaço público pela festa e pelos foliões, associando essa atitude a uma visão crítica com relação a essa crescente visão do carnaval enquanto produto a ser vendido. Para isso recuperam-se personagens tradicionais do carnaval, como o Zé Pereira, para recuperar a forma desordeira de organização da festa e sua forma, também caótica, de ocupar o espaço público. Para a Desliga dos Blocos, é através da desobediência presente no carnaval tradicional que vai se buscar uma nova opção de cidade e de postura, frente à política urbana que no Rio de Janeiro vem sendo imposta por conta dos megaeventos como Copa do Mundo (2014) e Olimpíadas (2016).

O carnaval é e sempre será um ato político (como demonstrou bem nes- se ano de 2010 o bloco "Vergonha da Zona Sul" que levou a banda de catadores e mendigos para a praia de Ipanema). É a incorporação da arte no cotidiano. Lutar para preservar sua potência é lutar por uma rua que nos é sempre tirada. Avancemos foliões nômades!! Viva o carnaval, viva o Zé Pereira e o Saci Pererê, viva o sorriso doce dos que desobedecem.... Em tempos de tanques nas ruas, não retrocedamos, com a certeza de que um dia, o exército de palhaços vencerá!! (DESLIGA DO BLOCOS - MANIFESTO NÔMADE)

As ligas/associações ocupam um espaço importante no carnaval dos blocos de rua do Rio de Janeiro hoje, elas funcionam como mediadoras entre blocos e empresas privadas com potencial de financiar a festa. Realizam também a mediação com o poder público quanto à organização do carnaval e com relação à fixação de significados para a tradição carnavalesca. São um campo privilegiado, dado à visibilidade que as ligas/associações têm na mídia, de determinar representações e disputar a tradição do carnaval carioca. Mesmo que com visões distintas e até opostas, o respeito à tradição do carnaval de rua do Rio de Janeiro é algo fundamental para as ligas/associações. As formas como elas buscam a valorização das tradições podem ser diferenciadas, via patrimonialização ou disputa da cidade, mas partem da ideia da preservação da memória e de sua prática como forma de lidar com a presença constante do diferente no carnaval, reconhecido através da categoria acusatória de baianização.

\section{Tradição e poder público: A normatização da festa}

O poder público, mais especificamente a Prefeitura Municipal do Rio de 
Janeiro, entra na discussão de tradição na festa carnavalesca através de ações que visam a normatização da festa. As ações de normatização da festa passam a acontecer de forma mais efetiva a partir da gestão do prefeito Eduardo Paes, iniciada em 2009. Essa normatização do carnaval de rua pode acontecer através de ações de patrimonialização dos blocos escolhidos como mais representativos, mas também de decretos e leis que organizam o carnaval de rua no Rio de Janeiro. Assim a tradição passa ser legitimada através do patrimônio e passa a ser respeitada através de uma série de definições sobre o que pode ou não acontecer no carnaval.

O poder público tendo como preocupação a permanência da festa com suas características tradicionais utiliza-se do instrumento da patrimonialização como forma de reconhecimento das manifestações culturais populares, como os blocos de carnaval, limitando-se a legitimá-las através de mecanismos legais, mas não garantindo a sua existência. $O$ reconhecimento de alguns blocos como patrimônio cultural de natureza imaterial carioca legitima esses blocos como tradicionais, mas não auxilia na sua sustentabilidade. Assim como qualquer exercício de valorização da memória, escolhe-se algo para lembrar e entender como tradicional, são eles: a Banda de Ipanema, declarada patrimônio em $2004^{\mathrm{VIII}}$; o bloco Cacique de Ramos, declarado patrimônio em 2005'x; e o Cordão da Bola Preta, declarado patrimônio em 2007x. Essas ações aconteceram no governo de César Maia, durante o mandato de Eduardo Paes voltou-se os esforços para organização da festa. O gênero musical da marchinha de carnaval, também foi considerado patrimônio cultural da cidade do Rio de Janeiro em $2015^{\mathrm{XI}}$, já na gestão Paes.

A tradição do carnaval de rua também é preservada a partir da organiza- ção da festa com decretos que determinam regras para o carnaval acontecer, sendo a principal delas a necessidade dos blocos pedirem autorização em período estabelecido pela prefeitura da cidade $^{\mathrm{XII}}$. Em 2013, a prefeitura cria a "Comissão Especial de Avaliação dos Blocos de Rua"XIII composta de nove representantes de diferentes secretarias do município e duas entidades representativas dos blocos e bandas tendo como critério para escolha destas a tradição e representatividade. Neste decreto o próprio poder público incorpora a noção de tradição como característica distintiva entre os blocos e ligas/associações, embora sem explicitar o seu significado. Neste mesmo decreto a prefeitura estabelece os critérios de avaliação dos blocos que são construídos a partir de dois argumentos, definição de tradicional enquanto representativo do carnaval de rua carioca e a relação dessa tradição com o território da cidade, argumento também utilizados por blocos e ligas/associações e, inclusive, dispostos como fundamentais através da mediação da Sebastiana. Os critérios para a autorização são:

I - a tradição do Bloco de Rua;

II - as características do Bloco em relação ao Carnaval de Rua do Rio de Janeiro;

III - as características do Bairro/Região onde pretende desfilar o Bloco;

IV - a relação que o Bloco de Rua mantém com a localidade/comunidade;

$\mathrm{V}$ - o local de realização do desfile pretendido;

VI - a estimativa de público;

VII - os possíveis impactos que possam interferir no dia-a-dia da localidade.

(RIO DE JANEIRO, Decreto No 37.182, de 20 de Maio de 2013)

O poder público, coligado com diferentes ligas/associações e com muitos blocos, opera sobre a tradicionalização 
da festa através de mecanismos de definição simbólica sobre a regulamentação da prática carnavalesca. A defesa da tradição e das características do carnaval dos blocos de rua no Rio de Janeiro se dá através de ações, legais e sociais, contra o uso de cordas identificando quem comprou o abadá, também proibindo a comercialização deste como pré-requisito para brincar o carnaval nos blocos de rua. Desta forma, blocos, ligas/associações e a prefeitura se posicionam contra a baianização do carnaval carioca e, através de decretos e do discurso, estabelecem os limites do que pode ou não acontecer no carnaval de rua da cidade.

Art. 10. Fica proibida, na Cidade do Rio de Janeiro, a delimitação de espaços, por meio de cordas e/ou seguranças ("áreas privadas"), pagos ou não, nos desfiles de blocos ou bandas de rua e nos ensaios carnavalescos de rua, no período de que trata o art. 10 do Decreto no 30.453/2009. Parágrafo único. Excepcionalmente, poderá ser delimitado espaço, por meio de cordas e/ou seguranças, para uso exclusivo dos integrantes da bateria e/ou da banda, bem como daqueles diretamente envolvidos na organização do desfile.

Art. 2o. Ficam automaticamente cassadas as autorizações já concedidas para os desfiles de blocos, bandas e ensaios carnavalescos que não respeitem o disposto neste Decreto.

$\S 20$ A RIOTUR, com o apoio da Guarda Municipal, adotará as medidas necessárias para coibir desfiles que contrariem o disposto neste Decreto.

Art. 3o. O não cumprimento do disposto no art. 10 implicará no indeferimento do pedido de autorização para desfile nos períodos carnavalesco e pré-carnavalesco do ano subsequente, nos termos do art. 14 do Decreto no $30.453 / 2009$.

(RIO DE JANEIRO, Decreto No 36.760, de 5 de Fevereiro de 2013)

Estabelecem-se, assim, fronteiras rígidas, entre o que pode ser considerado típico do carnaval de rua do Rio de Janeiro e o que representa expressões diferentes oriundas de outros carnavais. O não respeito a essas fronteiras será punido pelo não reconhecimento oficial do bloco através da autorização para o desfile no ano posterior, no âmbito da prefeitura, e a desvalorização do bloco no meio carnavalesco. A baianização torna-se assim categoria acusatória também utilizada pelo poder público, que ao mesmo tempo que combate a mercantilização da festa por parte dos blocos, privatiza o seu carnaval através de parcerias público-privadas. Assim, por meio de ações normatizadoras, tanto em termos organizacionais quanto simbólicos, por parte da Prefeitura Municipal do Rio de Janeiro, o poder público adentra o debate sobre os limites da prática carnavalesca tradicional e autêntica dos blocos de rua, legitimando e oficializando a distinção entre eles.

Sob todos os aspectos, o carnaval é a nossa principal manifestação cultural. Ele tem um papel no desenvolvimento da identidade do brasileiro e do carioca em especial que é absolutamente inigualável. [...] Carnaval é fundamental, ele tem uma função social, tem uma função de catarse coletiva, que é bacana, mas é aquela coisa de quando o carioca é mais carioca. Acho que esse é um dos pontos mais positivos. $E$ que bom que a gente tem visto nos últimos anos que o carioca quer ser carioca de novo.

(Alex Martins, Supervisor do carnaval dos blocos de rua na RIOTUR no governo Paes, em entrevista para a pesquisa.) 
Entendendo o carnaval como representação da identidade do carioca, o poder público ao buscar preservar sua memória, valoriza consequentemente a identidade (POLLAK, 1992) associada a ela. Através de discursos que retomam as práticas tradicionais os organizadores da festa justificam suas escolhas e usam de políticas públicas para preservação desse movimento de tradicionalização dos blocos. Tradicionalização aqui entendida não só como tradições inventadas (HOBSBAWAM, 1984), mas como "reflexão acompanhada da práxis das expressões advindas das tradições culturais" (TEIXEIRA, 2004, p. 09). Tradicionalização construída através de ações do poder público de patrimonialização e exercícios de definição do que é, e principalmente do que não pode ser. O carnaval dos blocos de rua no Rio de Janeiro hoje, busca respeitar a identidade local ao mesmo tempo que a transforma em produto a ser vendido para consumo externo, através da valorização do turismo.

\section{Considerações Finais}

A proposta de pensar processos de tradicionalização do carnaval dos blocos de rua carioca está diretamente associada com a discussão sobre a noção de tradição para os agentes que o organizam e vivenciam. A noção de tradição pode adquirir diferentes facetas, entre elas expressar uma relação direta com um tempo histórico determinado, quando a tradição é associada a fundação dos blocos, representando um exercício de construção de uma continuidade com o passado. Essa tradição histórica fica ainda mais forte se associada com um território específico. Assim a tradição passa a ser territorializada, critério que legitima a atuação dos blocos junto ao poder público e ligas/associações. Tradição, passa assim, a ser entendida como história e territorialidade.
Critérios estéticos, como uso de fantasia, e musicais, como respeito ao samba e suas variações, consolidam-se como elementos classificatórios da tradição de um bloco, embora com fronteiras menos rígidas que as anteriormente citadas. Todavia ajudam na construção da ideia da tradição associada a determinada prática espontânea e autêntica da expressão cultural carnavalesca carioca. Desta forma, passível de ser protegida através de processos de patrimonialização e normatização da festa, a tradição ganha contornos simbólicos de disputa por representação e identidade, ajudando como característica distintiva do carnaval de rua carioca com o de outros lugares do país.

É importante você ter a tradição, ela é importante para a nossa cultura, para a nossa identificação enquanto sociedade. Mas ela não pode ser uma coisa fechada. Até porque a cultura brasileira ela foi toda feita através de transformações de outras culturas. $O$ carnaval carioca, o próprio samba. [...] então você não pode fechar isso e não deixar mais a transformação acontecer. É importante que a gente se registre para que não se perca. Não se perca a tradição. Eu acho que perder a tradição é ruim, mas se engessar dentro de uma tradição também é ruim!

(Tiago Rodrigues, bloco Orquestra Voadora, em entrevista para a pesquisa.)

Tiago Rodrigues e o bloco Orquestra Voadora nos ajudam nesse entendimento de que a valorização da tradição, tenha ela o significado adquirido no contexto em que está inserida, representa uma ação processual e relacional. Processos de patrimonialização reconhecem e legitimam a tradição, mas para que o carnaval dos blocos de rua permaneça expressivo de uma prática, é necessário que os seus agentes ao 
mesmo tempo que adentram o campo de disputa pelo significado da tradição, continuem em um constante processo de (re)tradicionalização, ou seja, de invenções e reinvenções do carnaval de rua no Rio de Janeiro.

\section{Bibliografia}

BAKTHIN, Mikhail. A cultura popular na Idade Média e no Renascimento. Brasília: Ed. Da UnB, 1993.

FRYDBERG, Marina Bay, EIRAS, Rebeca Eler de Carvalho. "O abre alas, que eu quero passar": Contribuições para pensar a economia da festa através do carnaval dos blocos de rua na cidade do Rio de Janeiro. In: CASTRO, Flávia Lages de, TELLES, Mário F. De Pragmácio. Dimensões econômicas da cultura: Experiências no campo da Economia Criativa no Rio de Janeiro. Rio de Janeiro: Lumem Juris, 2015.

HERSCHMANN, Micael. Apontamentos sobre o crescimento do Carnaval de rua no Rio de Janeiro no início do século 21. Intercom - RBCC. São Paulo, v. 36, n. 2, jul./dez., 2013.

HOBSBAWM, Eric. Introdução: A Invenção das Tradições. In: HOBSBAWM, Eric; RANGER, Terence. A Invenção das Tradições. Rio de Janeiro: Paz e Terra, 1984.

LEFEBVRE, Henry. O direito à cidade. São Paulo: Editora Moraes, 1991.

POLLAK, Michael. Memória, esquecimento, silêncio. Estudos Históricos. Rio de Janeiro, vol. 2, no. 3, 1989.

POLLAK, Michael. Memória e Identidade Social. Estudos Históricos. Rio de Janeiro, vol. 5, $\mathrm{n}^{\circ} .10,1992$.

QUEIROZ, Maria Isaura Pereira de. Carnaval Brasileiro: O vivido e o mito. São Paulo: Brasiliense, 1999.
RIO DE JANEIRO (cidade). Decreto No 23.926 de 23 de janeiro de 2004. Declara Patrimônio Cultural Carioca A Banda de Ipanema. Disponível em: <http://www0.rio.rj.gov.br/patrimonio/pastas/legislacao/dec_23926.pdf> Acesso em: 1 fev. 2016.

RIO DE JANEIRO (cidade). Lei No 4.068 de 24 de maio de 2005. Declara Patrimônio Cultural do Povo Carioca o Bloco Carnavalesco Cacique de Ramos. Disponível em: <http://www.rio. rj.gov.br/dlstatic/10112/4368015/4108315/04L El4068BlocoCarnavalescoCaciquedeRamos. pdf> Acesso em: 1 fev. 2016.

RIO DE JANEIRO (cidade). Decreto $N^{\circ} 27.594$ de 14 de fevereiro de 2007. Declara patrimônio cultural carioca o Cordão da Bola Preta. Disponível em: $<$ http://www0.rio.rj.gov.br/patrimonio/pastas/legislacao/dec_27594.pdf> Acesso em: 1 fev. 2016.

RIO DE JANEIRO (cidade). Decreto $N^{\circ} 30.453$, de 09 de fevereiro de 2009. Determina as normas e procedimentos para a realização de desfiles de blocos e bandas carnavalescas no âmbito do Município do Rio de Janeiro e dá outras providências. Diário oficial do município, Rio de Janeiro, RJ, 9 fev. 2009. Disponível em: <http://smaonline.rio.rj.gov.br/legis_consulta/31123Dec\%20 30453_2009.pdf>. Acesso em: 1 fev. 2016.

RIO DE JANEIRO (cidade). Decreto No 30.659, de 07 de maio de 2009. Dispõe sobre as normas e procedimentos para os desfiles de blocos carnavalescos no Município do Rio de Janeiro. Diário oficial do município, Rio de Janeiro, RJ, 8 mai. 2009. Disponível em: <http://smaonline.rio.rj.gov.br/legis_consulta/31123Dec $\% 20$ 30453_2009.pdf>. Acesso em: 1 fev. 2016.

RIO DE JANEIRO (cidade). Decreto $N^{\circ} 37.182$, de 20 de maio de 2013. Dispõe sobre a Criação da "Comissão Especial de Avaliação de Blocos de Rua" na Cidade do Rio de Janeiro, e dá outras providências. Diário oficial do município, Rio de Janeiro, RJ, 21 mai. 2009. Disponível em: <https://leismunicipais.com.br/a/ rj/r/rio-de-janeiro/decreto/2013/3719/37182/ decreto-n-37182-2013-dispoe-sobre-a-criacao-da-comissao-especial-de-avaliacao-de-blocos-de-rua-na-cidade-do-rio-de-janeiro-e-da-outras-providencias>. Acesso em: 1 fev. 2016.

RIO DE JANEIRO (cidade). Decreto $N^{\circ} 36.760$, de 05 de fevereiro de 2013. Dispõe sobre a proibição da demarcação de áreas privadas nos blocos de carnaval na Cidade do Rio de Janeiro e dá outras providências. Diário oficial do município, Rio de 
Janeiro, RJ, 6 fev. 2013. Disponível em: < http:// www.legisweb.com.br/legislacao/?id=251074>. Acesso em: 1 fev. 2016.

RIO DE JANEIRO (cidade). Decreto $N^{\circ} 39.751$, de 05 de fevereiro de 2015. Declara patrimônio cultural carioca o gênero musical conhecido por marchinha de carnaval. Disponível em: <https:// leismunicipais.com.br/a1/rj/r/rio-de-janeiro/decreto/2015/3975/39751/decreto-n-39751-2015-declara-patrimonio-cultural-carioca-o-genero-musical-conhecido-por-marchinha-de-carnaval>. Acesso em: 1 fev. 2016.

TEIXEIRA, João Gabriel L. C. Apresentação. In: TEIXEIRA, João Gabriel L. C.; GARCIA, Marcus Vinícius Carvalho; GUSMÃO, Rita. Patrimônio imaterial, performance cultural e (re)tradicionalização. Brasília: ICS-UnB, 2004.

\section{Recebido em 09/12/2017}

Aprovado em 24/02/2018 pesquisa conta com o financiamento, através de bolsa de iniciação científica do CNPq e da Faperj, com o auxílio dos alunos do bacharelado em Produção Cultural da Universidade Federal Fluminense, Alex Kossak, Gustavo Portella Machado, Maria Emília Ribeiro Vasconcelos e Rebeca Eler de Carvalho Eiras.

VI Uma primeira versão desse texto foi apresentada na $30^{a}$ Reunião Brasileira de Antropologia, realizada entre o s dias 03 e 06 de agosto de 2016, João Pessoa /PB. Agradeço às organizadoras e participantes do GT Cultura Popular, patrimônio e performance pelo debate que enriqueceu a análise.

VII Desde 2014 venho fazendo de forma sistemática o levantamento do número de blocos que desfilam no carnaval de rua do Rio de Janeiro chegando a esse número até 2016 .

VIII DECRETO N 23.926 de 23 de janeiro de 2004 D.O.M. do Rio de Janeiro.: 26/01/2004.

IX LEI No 4.068 de 24 de maio de 2005. - D.O.M. do Rio de Janeiro: 06/06/2005.

X DECRETO N ${ }^{\circ} 27.594$ de 14/02/2007. - D.O.M. do Rio de Janeiro.: 15/02/2007.

XI DECRETO No 39.751 de 05/02/2015. - D.O.M. do Rio de Janeiro.: 06/02/2007.

XII DECRETO No 30.453 de 9 de fevereiro de 2009 , complementado e revogado pelo DECRETO $\mathrm{N}^{\circ}$ 30.659 de 7 de maio de 2009.

XIII DECRETO Nº 37.182 de 20 de maio de 2013.

I Marina Bay Frydberg. Doutora em Antropologia Social pela Universidade Federal do Rio Grande do Sul. Professora do Departamento de Arte da Universidade Federal Fluminense. Contato: marinafrydberg@gmail.com

II http://g1.globo.com/rio-de-janeiro/carnaval/2016/ noticia/2016/01/veja-lista-com-data-e-hora-de-desfile-dos-blocos-de-rua-do-rio-em-2016.html - Acessado em 06/03/2016.

III Considerando o carnaval das escolas de samba e dos blocos.

IV http://www.rio.rj.gov.br/web/riotur/ exibeconteudo ? id=5914149

- Acessado em 06/03/2016.

V Este artigo é resultado de uma pesquisa maior que se iniciou em 2014 junto ao Observatório de Economia Criativa do Estado do Rio de Janeiro, contando com financiamento do Ministério da Cultura. Desde 2015 a 